\title{
Laure Michel, Delphine Rumeau (dir.), Les poésies de langue française et l'histoire au $\mathrm{XX}^{\mathrm{e}}$ siècle
}

\section{Emanuela Cacchioli}

\section{(2) OpenEdition}

\section{Journals}

\section{Edizione digitale}

URL: http://journals.openedition.org/studifrancesi/1641

DOI: 10.4000/studifrancesi.1641

ISSN: 2421-5856

\section{Editore}

Rosenberg \& Sellier

\section{Edizione cartacea}

Data di pubblicazione: 1 novembre 2014

Paginazione: 641-642

ISSN: 0039-2944

\section{Notizia bibliografica digitale}

Emanuela Cacchioli, « Laure Michel, Delphine Rumeau (dir.), Les poésies de lanque française et l'histoire au $x x^{\mathrm{e}}$ siècle », Studi Francesi [Online], 174 (LVIII | III) | 2014, online dal 01 novembre 2014, consultato il 18 septembre 2020. URL : http://journals.openedition.org/studifrancesi/1641 ; DOI : https://doi.org/ 10.4000/studifrancesi.1641

Questo documento è stato generato automaticamente il 18 settembre 2020.

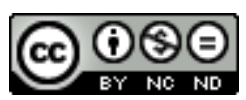

Studi Francesi è distribuita con Licenza Creative Commons Attribuzione - Non commerciale - Non opere derivate 4.0 Internazionale. 


\title{
Laure Michel, Delphine Rumeau (dir.), Les poésies de langue française et l'histoire au $\mathrm{XX}^{\mathrm{e}}$ siècle
}

\author{
Emanuela Cacchioli
}

\section{NOTIZIA}

LAURE MICHEL, DELPHINE RUMEAU (dir.), Les poésies de langue française et l'histoire au XXe siècle, Rennes, Presses Universitaires de Rennes, 2013, «Plurial», pp. 210.

1 Il volume è una collettanea che riunisce gli atti di due giornate di studi tenutesi presso le università di Nizza nel 2010 e di Tolosa nel 2012. Gli incontri si proponevano di riflettere sulla poesia francese, francofona e postcoloniale e di indagare le specificità di ciascuna di esse e il loro legame con la storia. In particolare, si è analizzato come e quanto la poesia abbia inciso sugli eventi contemporanei. Sono state, inoltre, considerate le modalità di rappresentazione degli avvenimenti storici e il loro legame con il tempo collettivo. Nell'introduzione (pp. 9-30), Laure MICHEL e Delphine RUMEAU mettono in rilievo che, per quanto generalmente tacciata di un formalismo che la renderebbe incapace di farsi carico degli eventi collettivi, la poesia francese è in realtà un terreno di dibattito, o addirittura di contestazione delle riflessioni sulla storia contemporanea che trovano delle configurazioni inedite. La poesia francofona, al contrario, sia coloniale che postcoloniale, si focalizza sulla memoria collettiva e sul rapporto che intercorre tra poesia e linguaggio.

2 Sebbene, a detta delle curatrici, sia impossibile separare nettamente poesia francese e poesia francofona, la raccolta di saggi è di fatto bipartita e il volume rispetta tale suddivisione. Nell'articolo che apre l'opera (Une diérèse dans "Le Crève-coeur" d'Aragon, pp. 31-45), Jean-François PUFF si interroga sulle possibili rappresentazioni poetiche che possono nascere in seguito a una sconfitta bellica. Nel caso di Aragon, il risultato corrisponde alla ricostruzione di una verità resa in modo controllato attraverso la 
specificità formale. Ad una conclusione simile giunge Jean-Pierre ZUBIATE in Le mythe à l'épreuve de l'histoire dans "Les Rois Mages" d'André Frénaud (pp. 47-65): la poesia di Frénaud si pone all'origine di un movimento di emancipazione che consente di superare la negatività della sconfitta e di compiere un gesto creatore personale $e$ collettivo. Quest'ultima dimensione è anche al centro delle preoccupazioni di Reverdy. Secondo Benoît MONGINOT (L'Histoire, "de la main à la main»: subjectivation, valeur et figurations de l'Histoire dans "Le Chant des morts" (1944-1948) de Pierre Reverdy, pp. 67-83), con la scrittura poetica, l'autore ricerca una risposta etica e politica, in quanto una comunità è tale se lascia spazio alla voce di ciascuno. Laure MICHEL (Benjamin Fondane et les fantômes de l'Histoire, pp. 85-100) si sofferma, invece, sulla contraddizione che caratterizza l'essere poeta: il ricorso al linguaggio mostra un carattere ideale e evanescente. L'unico modo per uscire dall'impasse consiste nella creazione di un'elegia. Lucie таї̈вB (Lire la présence de l'Histoire dans “Le Livre des Questions", pp. 101-112) analizza il testo di Jabès in quanto antidoto al silenzio che accompagna l'esperienza del campo di concentramento. Il volume prosegue con una serie di articoli dedicati alle letterature francofone. In Le chant ventriloque de Tchicaya U Tam'si (pp. 113-132), Cyrille FRANçoIs riflette sulla rappresentazione della storia contemporanea in poesia e ne deduce che, per quanto tragici, i componimenti lasciano filtrare un barlume di speranza (la tensione tra quest'ultima e la disperazione caratterizza una visione lucida della contemporaneità). Segue l'articolo di Delphine RUMEAU (Aimé Césaire et Gaston Miron, «se dresser dans l'appel d'une mémoire osseuse», pp. 133-145) che affronta la necessità dei due poeti di riconquistare un passato perduto a causa dell'azione del colonizzatore. La stessa ricerca di storie antiche e anonime e la relazione tra tempo e spazio sono

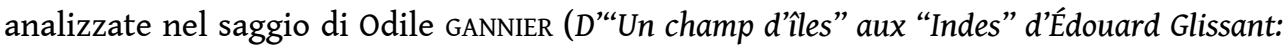
"ce que le Chant dira», pp. 148-158). Éric TRUDEL si sofferma, invece, sulla poesia quebecchese con «Avant qu'elle soit le dit des statues»: l'histoire au lieu du poème de Fernand Ouellette (pp. 159-174) per constatare che il rapporto tra poesia e storia è allo stesso tempo fondativo e inesistente, data la particolare condizione culturale in cui si trova il Québec. La poesia contemporanea viene affrontata da Jonathan LIVERNoIs, In Rapatriement à Mirabel: à propos de "Lignes aériennes" (2002) de Pierre Nepveu (pp. 175-188). Nel saggio si può vedere come il poeta avverta la necessità di ricostruire pazientemente la sua memoria storica e come debba assumere il passato nella sua complessità. Chiude la collettanea D'un traditionalisme l'autre: Rabearivelo, la Romanie française et la piété que l'on doit aux morts (pp. 189-208) di Christophe IMBERT. Il critico si propone di affrontare la poesia dell'autore malgascio senza preconcetti, ma cercando di rintracciare il legame tra affermazione della propria identità e prestito di modelli stranieri.

3 Il volume coglie il momento di grande proliferazione di testi dedicati allo studio comparato delle letterature francesi e francofone e cerca di colmare una carenza di pubblicazioni di ambito poetico. Per ottenere tale risultato, l'opposizione tra i due poli viene sfumata in favore dello studio di dinamiche e di analogie di rappresentazione della storia che mettano in luce quanto le poesie di lingua francese si nutrano dei paradossi che caratterizzano il loro rapporto con gli eventi contemporanei. 